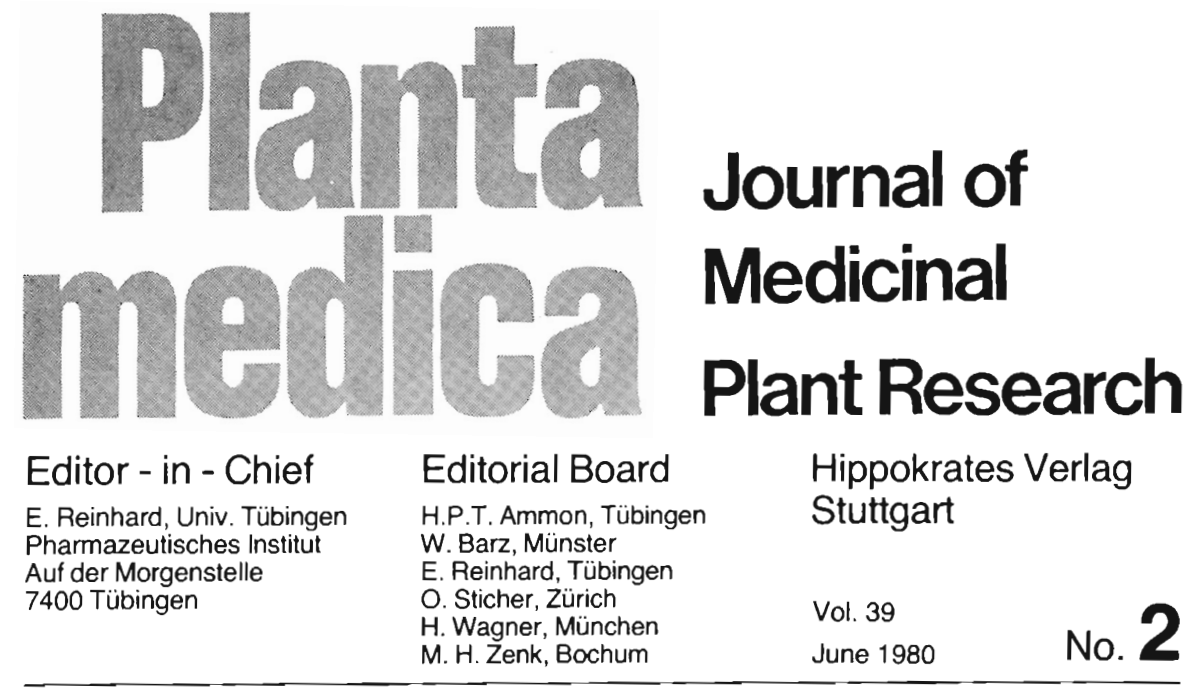

\title{
Some Aspects of the Carbazole Alkaloids
}

\author{
D. P. Chakraborty
}

Bose Institute, Calcutta 700009, India.

Key Word Index: Rutaceae; Carbazole Alkaloids; Structural Elucidation; Synthesis; Biomimetic Reactions; Biosynthesis.

\section{Introduction}

We have been interested in some members of the family Rutaceae because of different views expressed in the placement of the order Rutales in Angiosperm taxonomy [1-4]. Hurchinson [3] places the order in his Lignosae far away from Geraniales which is in his Herbaceae while others advocate its place very near
Geraniales. Aromatics, aromatics with MVA* derived units and degraded triterpenoids of the limonin group are some characteristic compounds (Fig. 1, I-IX) of the family. Among the members of the aromatics with MVA-units, alkaloids derived from anthranilic acid constitute a major group. Thus, furoquinolines, acri-

\footnotetext{
* Abbreviation: $M V A=$ mevalonic acid;
} 
dones, quinolines, indoloquinolines and quinazolones are the major alkaloids of the family. The role of anthranilic acid in building these alkaloids was pointed out by PrICE [5] as early as 1955 . Subsequent- ly PrICE [6] pointed out the taxonomic implications of these constituents.

In the course of our work on the che- $y$ mistry of Rutaceae, we have come across

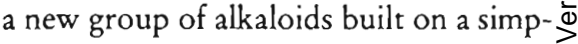<smiles>CNc1ccccc1C(=O)O</smiles><smiles>CC1(C)C=CC2C(=O)Nc3ccccc3C2O1</smiles>

IV<smiles></smiles>

VI

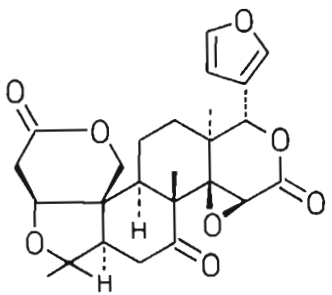

VIII<smiles>c1ccc2ncccc2c1</smiles>

II<smiles>COC1=C2CCOC2=NC2C=CC=CC12</smiles>

III<smiles>O=c1nc(Cc2ccccc2)[nH]c2ccccc12</smiles>

v<smiles>O=c1ccc2cc3ccoc3cc2o1</smiles>

VII

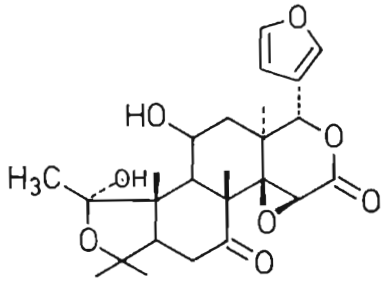

IX

Fig. 1. Characteristic compounds of the Family Rutaceae. 
le carbazole skeleton which could be considered to be formally derived from anthranilic acid. Some aspects of these alkaloids form the subject of the present discussion.

Carbazole (X) was isolated as early as 1872 from coal tar by GraEbE and GLAZER. Its occurrence [7] in plants was not reported until 1964-65 when the structure of murrayanine (XI) the first member of carbazole alkaloids was reported. Since then, nearly 36 structurally different carbazole alkaloids have been reported which could be broadly classified into 3 main groups:

members with $\mathrm{C}-13$ carbon skeleton (fig. 5),

members with C-18 carbon skeleton (fig. 9 and 10 ) and

members with $\mathrm{C}-23$ carbon skeleton (fig. 12).

\section{Structures of some important members}

\section{Members of the $\mathrm{C}-13$ skeleton group}

Murrayanine [7], $\mathrm{C}_{14} \mathrm{H}_{11} \mathrm{NO}_{2}\left(\mathrm{M}^{+} 225\right)$ (XI; fig. $2 \mathrm{~A}$ ) was isolated from the petroleum ether extract of Murraya koenigii Spreng. The UV spectrum of the compound was significantly characteristic for 3-formyl carbazole. On potassium borohydride reduction it afforded an alcohol (XII) having UV spectrum characteristic for 1-methoxy carbazole indicating the alkaloid to be a 3-or 6-formyl-1-methoxy carbazole. The diagnostic spectral characteristics of formyl carbazoles reported by Buchi and WarRenhoff [8] and those of methoxy groups reported by our group [9] have been fruitfully utilised in assigning the positions of the formyl and methoxy groups in different carbazole alkaloids. NMR data were consistent with a carbazole derivative with a methoxy and aldehyde function on it.

On zinc dust distillation murrayanine furnished carbazole $(\mathrm{X})$ while its WolfFKishner reduction product furnished 3methyl carbazole (XIII) confirming the position of the formyl group at 3-position On decarbonylation the alkaloid furnished 1-methoxy carbazole (XIV). From all these data, the formulation of murrayanine as 1-methoxy-3-formyl carbazole was advanced which was substantiated by our synthesis. Another synthesis was reported by Crum and Sprague [7] just after we completed our synthesis. In our synthesis (fig. 2 B) 2-hydroxymethylene-5-methyl cyclohexanone (XV) on condensation with phenyl diazonium chloride (XVI) under JaPp-KLINGEMANN condition [10] gave 4-methyl cyclohexane-1,2,dione-1-phenyl hydrazone (XVII) which on cyclization with a mixture of acetic acid and hydrochloric acid furnished 1-oxo-3-methyl-1,2,3,4-tetrahydro carbazole (XVIII). On dehydrogenation (XVIII) furnished 1-hydroxy3 -methyl carbazole, the 0-methyl derivative of which on treatment with $\mathrm{N}$-bromosuccinimide in presence of traces of benzoyl peroxide and hydrolysis (in situ) furnished 1-methoxy-3-hydroxymethyl carbazole (XIX). This on oxidation with active $\mathrm{MnO}_{2}$ furnished murrayanine (XI).

It is evident that the structure of murrayanine has an anthranilic acid pattern. So it was of interest to look for carbazoles in a plant elaborating alkaloids derivable from anthranilic acid. The genus Glycosmis is taxonomically closely related to the genus Murraya and it has been repor- 
<smiles>COc1cc(C=O)cc2c1[nH]c1ccccc12</smiles>

$X I$

XII

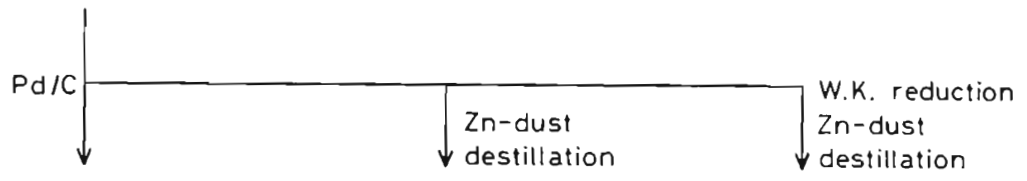<smiles>COc1cccc2c1[nH]c1ccccc12</smiles>

XIV<smiles>c1ccc2c(c1)[nH]c1ccccc12</smiles>

$x$<smiles>Cc1ccc2[nH]c3ccccc3c2c1</smiles>

XIII

Fig. 2. A) Chemical reactions for structural elucidation of murrayanine (XI).

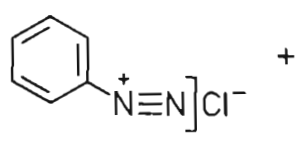

$X V I$<smiles>CC1CCC(=CO)C(=O)C1</smiles>

$X V$<smiles>CC</smiles><smiles>CC1CCC(=NNc2ccccc2)C(=O)C1</smiles>

XVII<smiles>Cc1cc(O)c2[nH]c3ccccc3c2c1</smiles><smiles>[V]C1CCCCC1</smiles><smiles></smiles><smiles>CC1CC(=O)c2[nH]c3ccccc3c2C1</smiles>

XVIII<smiles>COc1cc(CO)cc2c1[nH]c1ccccc12</smiles>

XIX

B) Synthetic route to $\mathrm{XI}$. 
<smiles>COc1ccc2[nH]c3ccc(C)cc3c2c1</smiles>

$x x$<smiles>COc1cc2[nH]c3ccc(O)cc3c2cc1C</smiles>

XXIII<smiles>COc1ccc2[nH]c3cc(OC)c(C)cc3c2c1</smiles>

$X X I$<smiles>COc1cc2[nH]c3ccc(OC(C)=O)cc3c2cc1C</smiles>

$X X I I$

Fig. 3. Structures of carbazoles from Glycomis pentaphylla (Retz) DC. and important analogues.

ted to elaborate [6] furoquinoline, acridone and quinazolone alkaloids which are formally derived from anthranilic acid. We therefore examined the root bark of Glycosmis pentaphylla (RETz) DC. from which we reported two carbazole alkaloids (fig. 3) glycozoline (XX) and glycozolidine (XXI); their structures have been deduced from physical data, degradative reactions and synthesis.

The UV spectral data have been used with diagnostic precision in deducing the structures of these compounds. Glycozoline had the UV spectrum similar to 3 methoxy carbazole. The $\mathrm{O}$-acetate XXII of the phenol XXIII obtained by a pre- ferential demethylation of glycozolidine with $\mathrm{HBr}$ showed UV spectrum similar to that of 2-methoxy carbazole. It suggests the placement of one of the methoxyl groups at 2-position. The isolation of glycozoline provided circumstantial evidence for the formation of the carbazole alkaloids through the anthranilate pathway. In course of our synthesis of glycozolidine, we developed a method for the synthesis of carbazoles from diphenylamine (fig. 4). It has been found that the diphenylamines XXIV-XXVII in presence of elemental iodine and oxygen cyclise to carbazoles at $350^{\circ} \mathrm{C}$ in a sealed tube.<smiles>[R3]c1ccc(Nc2ccc([R2])c([R])c2)cc1</smiles>

XXIV $\quad R_{1}=R_{2}=R_{3}=H$

$X X V \quad R_{1}=R_{3}=H ; R_{2}=C_{3}$

XXVI $\quad R_{1}=H ; R_{2}=C_{3} ; R_{3}=O M e$

XXVII $R_{1}=O M e ; R_{2}=C_{3} ; R_{3}=O M e$<smiles>[R3]c1ccc2[nH]c3cc([R2])c([R2])cc3c2c1</smiles>

$\times \quad R_{1}=R_{2}=R_{3}=H$

XIII $R_{1}=R_{3}=H ; R_{2}=C_{3}$

$X X \quad R_{1}=H ; R_{2}=C_{3} ; R_{3}=O M e$

$X X I \quad R_{1}=O M e ; R_{2}=C_{3} ; R_{3}=O M e$

Fig. 4. Widely applicable synthesis of carbazoles from diphenylamines. 
The reaction has been applied to the synthesis of various carbazoles and the yield in the cases of carbazole and 3-methyl carbazole are good. Recently, aniline has also been shown to cyclise to carbazole under these conditions. A free radical mechanism involving successive hydrogen abstraction for cyclisation [7] has been suggested. So fbr nine carbazole alkaloids with C-13 skeleton have been reported (fig. 5).

\section{Members of the $C-18$ skeleton group}

Girinimbine (fig. 6, XXVIII), $\mathrm{C}_{18} \mathrm{H}_{17} \mathrm{NO}$, mp $176^{\circ}$, the first member of the $\mathrm{C}-18$ skeleton group was isolated by us from the stem bark of Murraya koenigii Spreng. The UV and IR data showed the compound to belong to the carbazole group. A six proton singlet at $\delta 1.42$ in NMR spectrum of XXVIII together with the symmetrical doublet at $\delta 5.45$ and $\delta$ 6.25 suggested the presence of a 2:2-dimethyl- $\Delta^{3}$-pyran ring in the compound. Like 2:2-dimethyl- $\Delta^{3}$-chromenes [11] the mass spectrum of girinimbine shows a high intensity peak at $\mathrm{m} / \mathrm{e} 248$ which could be represented by the carbazolopyrillium ion XXIX.

The ionic species or species related to it, has been found to be characteristic for compounds with 2:2-disubstituted $\Delta^{3}$ pyrano-carbazole of $\mathrm{C}-18$ or C-23 skeleton. The isolation of 3-methyl carbazole by zinc dust distillation of girinimbine confirmed its 3-methyl carbazole skeleton. The UV spectrum of dihydrogirinimbine was similar to that of 2-methoxy

\begin{tabular}{|c|c|}
\hline 3-Methyl carbazole & $\begin{array}{l}R_{1}=R_{2}=R_{4}=R_{5}=H ; \\
R_{3}=M e\end{array}$ \\
\hline Murrayanine & $\begin{array}{l}R_{1}=O M e ; R_{2}=R_{4}=R_{5}=H ; \\
R_{3}=C H O\end{array}$ \\
\hline Mukoeic acid & $\begin{array}{l}R_{1}=O M e ; R_{3}=C O O H ; \\
R_{2}=R_{4}=R_{5}=H\end{array}$ \\
\hline Glycozoline & $\begin{array}{l}R_{1}=R_{2}=R_{5}=H ; R_{3}=M e ; \\
R_{4}=O M e\end{array}$ \\
\hline Glycozolidine & $\begin{array}{l}R_{1}=R_{5}=H ; R_{2}=R_{4}=O M e ; \\
R_{3}=M e\end{array}$ \\
\hline Mukonine & $\begin{array}{l}R_{1}=O M e ; R_{3}=\text { COOMe } \\
R_{2}=R_{4}=R_{5}=H\end{array}$ \\
\hline Mukonidine & $\begin{array}{l}R_{1}=R_{4}=R_{5}=H ; R_{2}=O H \\
R_{3}=\text { COOMe }\end{array}$ \\
\hline Mukoline & $\begin{array}{l}\mathrm{R}_{1}=\mathrm{R}_{2}=\mathrm{R}_{4}=\mathrm{H} ; \mathrm{R}_{3}=-\mathrm{CH}_{2} \mathrm{OH} ; \\
\mathrm{R}_{5}=\mathrm{OMe}\end{array}$ \\
\hline Mukolidine & $\begin{array}{l}R_{1}=R_{2}=R_{4}=H ; R_{3}=-C H O ; \\
R_{5}=-O M e\end{array}$ \\
\hline
\end{tabular}

Fig. 5. Structures of presently known C-13 carbazoles. 
<smiles></smiles>

XXIX<smiles>CC(=O)Oc1c(C)cc2c([nH]c3ccccc32)c1C=O</smiles>

$X X X I$<smiles>Cc1cc2c([nH]c3ccccc32)c(C=O)c1O</smiles>

$x x x$<smiles></smiles>

XXVIII<smiles>Cc1cc2c(cc1O)[nH]c1ccccc12</smiles>

$X X X I I$<smiles>COc1cc2[nH]c3ccccc3c2cc1C</smiles>

$x \times x I I I$

Fig. 6. Reactions leading to the structural elucidation of girinimbine (XXVIII).

carbazole showing the ether oxygen to be at 2-position. The proof for the fusion of the pyran ring at $2: 1$ position has been provided by the results (fig. 6) of ozonisation of girinimbine when the hydroxyaldehyde (XXX), mp $193^{\circ}$ was obtained. The o-acetate (XXXI) of this aldehyde showed a UV spectrum very similar to that of 1 -formyl carbazole suggesting the aldehyde group was attached to $C-1$. On decarbonylation, the aldehyde afforded a phenolic carbazole (XXXII) mp 243․ The o-methyl derivative XXXIII of XXXII, mp $225^{\circ}$ showed a UV spectrum similar to that of 2-methoxy carbazole. On decarbonylation the aldehyde furnished 2-hydroxy-3-methyl carbazole. From all these data the structure of the aldehyde (XXX) was considered to be 1formyl-2-hydroxy-3-methyl carbazole 
and girinimbine could be formulated as XXVIII. This structure was also proposed by Durta et al. on the interpretation of NMR and UV data.

The structure of girinimbine has been confirmed by three syntheses. In our synthesis (fig. 7) 2:2-dimethyl acrylyl chloride XXXIV was condensed with 2hydroxy-3-methyl carbazole (XXXV) at $5^{\circ} \mathrm{C}$ whenwas obtained, $\mathrm{mp} 200^{\circ}$. This on Fries rearrangement and cyclisation gave the indolochromanone XXXVII $\mathrm{C}_{18} \mathrm{H}_{1}>\mathrm{NO}_{2}$ mp. $60-65^{\circ}\left(\lambda \stackrel{\text { max }}{\mathrm{E}_{1} \mathrm{OH}} 228,282\right.$,e $4.65,4.09,4.22)$. The chromanone was reduced with sodium borohydride when the alcohol XXXVII, $\mathrm{C}_{18} \mathrm{H}_{19} \mathrm{NO}_{2}, \mathrm{mp}$ $160^{\circ}$ was obtained. The alcohol XXXVII on dehydration via its tosyl derivative in presence of collidine furnished girinimbine (XXVIII).
In connection with the ozonisation reaction of pyranocarbazole, we may cite the ozonization of heptazolidine (XXXIX; fig. 9), which has thrown some light on our existing ideas about attack of ozone on the pyran ring. In previous reports on the ozonisation of alkaloids and coumarins with 2:2 dimethyl- $\Delta^{3}$-pyran the $\alpha$-hydroxy aldehyde and acetone (XXXVIII) were considered as a conclusive proof for the presence of a 2:2-dimethylene- $\Delta^{3}$-pyran system. No clear picture of the way ozone attacked the molecule was available. The isolation (fig. 8) of the dialdehyde XL, $\alpha$-hydroxyaldehyde XLI and acetone shows that ozone attacks the double bond in the usual way and furnishes the dialdehyde type of compounds which undergoes either cleavage and decarboxylation and oxidation<smiles>Cc1cc2c(cc1O)[nH]c1ccccc12</smiles>

XXXII<smiles>CC(C)=CCl</smiles>

XXXIV<smiles>C=C(C)/C=C(/C)Oc1cc2[nH]c3ccccc3c2cc1Cl</smiles>
$X X X V I$<smiles>Cc1cc2c([nH]c3ccccc32)c2c1OC(C)(C)CC2=O</smiles>

$X X X V I$<smiles></smiles>

XXVIII

Fig. 7. Synthesis of girinimbine (XXVIII). 
<smiles>COc1cc2c([nH]c3ccc(C)cc32)c(C=O)c1OC(C)(C)C</smiles>

$X L$<smiles>COc1cc2c([nH]c3ccc(C)cc32)c(C=O)c1O</smiles>

$X L I$

Fig. 8. Carbazoles isolated after ozonolysis of heptazolidine (XXXIX in fig. 10).<smiles></smiles>

$\begin{array}{ll}\text { Girinimbine } & R_{1}=M e ; R_{2}=R_{3}=R_{4}=H ; \\ \text { Murrayacine } & R_{1}=C H O ; R_{2}=R_{3}=R_{4}=H ; \\ \text { Koenimbine } & R_{1}=M e ; R_{2}=O M e ; R_{3}=R_{4}=H ; \\ \text { Koenine } & R_{1}=M e ; R_{2}=O H ; R_{3}=R_{4}=H ; \\ \text { Koenigicine } & R_{1}=M e ; R_{2}=R_{3}=O M e ; R_{4}=H . \\ \text { Heptazolidine } & R_{1}=O M e ; R_{2}=M e ; R_{3}=R_{6}=H \\ \text { Koenigine } & R_{1}=M e ; R_{2}=O M e ; R_{4}=H ; R_{3}=O H\end{array}$

Fig. 9. Structures of presently known 2,2-dimethyl- $\Delta^{3}$-pyrano carbazoles.

to yield acetone and $\alpha$-hydroxy aldehyde.

While 2:2-dimethyl- $\Delta^{3}$-pyrano carbazole (fig. 9) forms a major number of C18 skeleton group, members with dimethyl allyl chain in the oposition of the phenolic hydroxyl at 2-position are known (fig. 10). Thus, we have so far 7 - pyrano carbazoles while 5 carbazoles with dimethyl allyl residue are known.

Members of the C-23 skeleton group

Mahanimbine, (XLII; fig. 11), $\mathrm{C}_{23} \mathrm{H}_{25} \mathrm{NO}$, mp. 94-95 $\mathrm{CM}^{+}$331) $[\alpha]_{\mathrm{D}}^{\mathrm{CHCL}} 345.4^{\circ}$, the first member of C-23 carbazole alkaloids was isolated by us from the stem bark of Murraya koenigii Spreng. Its UV spectrum was similar to that of girinimbine suggesting the presence of a pyrano carbazole skeleton like girinimbine. This was confirmed by the mass spectral data of mahanimbine when the high intensity peak at m/e 248 characteristic for the carbazole-pyrilium ion was observed. From the NMR data and some reactions we concluded that like girinimbine (XXVIII) it had a 2:2 dimethyl- $\Delta^{3}$-pyran ring and a $\mathrm{C}_{5} \mathrm{H}_{9}$ residue containing unsaturation. The complete structure of mahanimbine was proposed<smiles>[R]c1cc2c([nH]c3c([R6])c([R5])c([R4])cc32)c([R])c1[R]</smiles>

$\begin{array}{ll}\text { Heptaphylline } & \mathrm{R}_{1}=-\mathrm{CH}_{2} \mathrm{CH}=\mathrm{C}<; \mathrm{R}_{2}=\mathrm{OH} ; \mathrm{R}_{3}=\mathrm{CHO} ; \mathrm{R}_{4}=\mathrm{R}_{5}=\mathrm{R}_{6}=\mathrm{H} \\ \text { Heptazoline } & \mathrm{R}_{1}=\mathrm{CH}_{2}-\mathrm{CH}=\mathrm{C}<; \mathrm{R}_{3}=\mathrm{CHO} ; \mathrm{R}_{2}=\mathrm{R}_{6}=\mathrm{OH} ; \mathrm{R}_{4}=\mathrm{R}_{5}=\mathrm{H} \\ \text { 6-Methoxyheptaphylline } & \mathrm{R}_{1}=\mathrm{CH}_{2}-\mathrm{CH}=\mathrm{C}<; \mathrm{R}_{3}=\mathrm{CHO} ; \mathrm{R}_{2}=\mathrm{OH} ; \mathrm{R}_{4}=\mathrm{OMe} ; \mathrm{R}_{5}=\mathrm{R}_{6}=\mathrm{H} \\ \text { Indizoline } & \mathrm{R}_{1}=\mathrm{OMe} ; \mathrm{R}_{3}=\mathrm{CHO} ; \mathrm{R}_{2}=\mathrm{CH}_{2}-\mathrm{CH}=\mathrm{C}<; \mathrm{R}_{4}=\mathrm{R}_{5}=\mathrm{R}_{6}=\mathrm{H} \\ \text { Clausanitin } & \mathrm{R}_{1}=\mathrm{R}_{4}=\mathrm{R}_{6}=\mathrm{H} ; \mathrm{R}_{2}=\mathrm{OH} ; \mathrm{R}_{3}=\mathrm{CHO} ; \mathrm{R}_{5}=-\mathrm{CH}_{2}-\mathrm{CH}=\mathrm{C}<\end{array}$

Fig. 10. Structures of presently known dimethylallyl carbazoles. 
<smiles>Cc1cc2c(cc1O)[nH]c1ccccc12</smiles>

$X X X 11$<smiles>CC(C)=CCCC(C)C=O</smiles>

XLIII<smiles>Cc1cc2c([nH]c3ccccc32)c2c1OC(C)(C)C=C2</smiles>

$X$ LII

Fig. 11. Structure and synthesis of $\mathrm{C}-23$ carbazole mahanimbine (XLI).

by Narasimhan [12] from the precise analysis of the NMR, the UV data and the isolation of an 1-formyl carbazole derivative by ozonisation as XLII. Th $\alpha$-hydroxy aldehyde obtained by ozonisation of mahanimbine was fully characterized by Joshr et al. [13] as 1-formyl-2-hydroxy-3-methyl carbazole (XXX in fig. 6) which fully supported Narashimham's structure.

The structure of mahanimbine was confirmed by synthesis [7] by us as follows (fig. 11). 2-Hydroxy-3-methyl carbazole (XXXII) was condensed with citral (XLIII) in presence of pyridine in the cold when mahanimbine was obtained.
Other syntheses [7] also appeared almost simultaneously. The condensation of citral with the above phenolic substrate was accomplished under different experimental conditions by several workers.

The monoterpene unit in mahanimbine has given expression to pentacyclic and hexacyclic bases. Of these, murrayazoline (XLIV in fig. 12) $\mathrm{C}_{23} \mathrm{H}_{25} \mathrm{NO}\left(\mathrm{M}^{+}\right.$ 331) $[\alpha]_{D}-11^{\circ}$, mp $260-62^{\circ}$ was isolated by us in 1966. Later its racemate named mahanimbidine and curryangin was isolated from the leaves and the stem bark of the plant. On the basis of nmr and mass spectral data Popu et al. [14] as well as Dutra et al. [15] advanced the structure<smiles>CC1=CC2=C3c4c(cc(C)cc4-c4ccccc4N3C2(C)C)O1</smiles>

XLIV

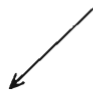<smiles>Cc1cc2c([nH]c3ccccc32)c2c1OC1(C)CCC(C(C)(C)O)C2C1</smiles>

$X L V$<smiles>C=C(C)C1CCC2(C)CC1c1c(c(C)cc3c1[nH]c1ccccc13)O2</smiles>

$X$ LVI

Fig. 12. Structures of pentacyclic and hexacyclic C-23 carbazoles. 


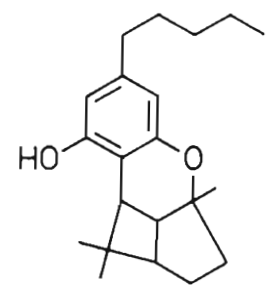

L

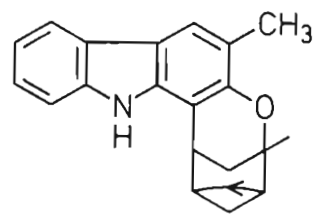

$X L V I I$

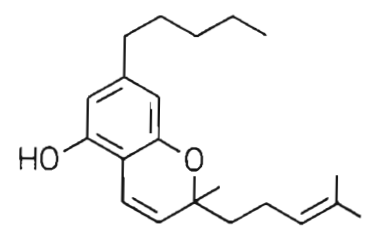

LIX

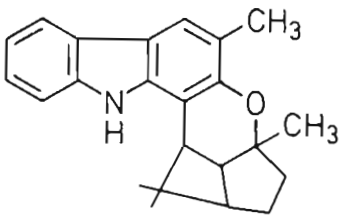

XLVIII

Fig. 13. Structures of various aromatics indicating possible arrangements of a. $\mathrm{C}_{10}$ unit.

of mahanimbidine as (XLIV). Durra ed al. also obtained the compound during $\mathrm{SnCl}_{2}$ catalysed cyclisation of citral with 2-hydroxy-3-methyl carbazole.

It was observed by us that during attempted hydrogenation in acetic acid of murrayazoline, a compound $\mathrm{C}_{23} \mathrm{H}_{27} \mathrm{NO}_{2}, \mathrm{M}^{+} 349$, was obtained. On chromic acid oxidation murrayazoline furnished acetone. These reactions of murrayazoline prompted us to undertake the $\mathrm{x}$-ray crystallographic studies with the collaboration of Dr. Bordner [16] to confirm the hexacyclic structure of the base.

We isolated from the stem bark of the plant, murrayazolinine (XLV) $\mathrm{C}_{23} \mathrm{H}_{27} \mathrm{NO}_{2}$ identical with the compound obtained by acid catalysed hydration of murrayazoline (XLIV). The first pentacyclic carbazole alkaloid murrayazolidine, (XLVI) $\mathrm{C}_{23} \mathrm{H}_{25} \mathrm{NO}, \mathrm{mp} 141^{\circ}[\alpha]_{\mathrm{D}} 20^{\circ}$ was also obtained from the stem bark of the plant. This compound was obtained as a racemate and named as cyclomahanimbine or currayanine by different wor-<smiles></smiles>

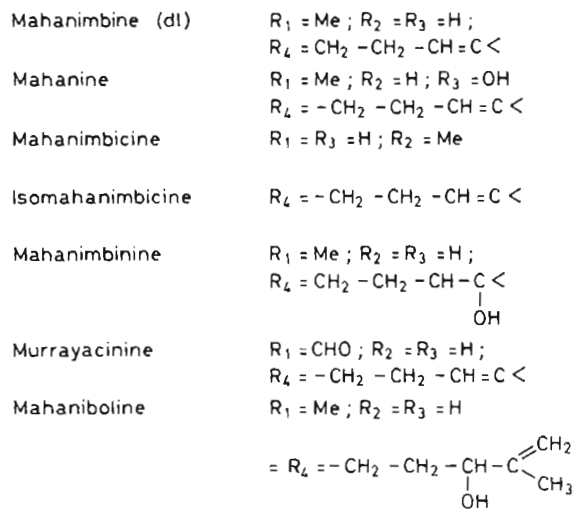

Fig. 14. Structures of carbazoles with a $\mathrm{C}_{10}$-monoterpene unit. 
kers. The interrelationship between murrayazoline (XLIV) murrayazolinine (XLV) and murrayazolidine (XLVI) has been established by a series of reactions [7] starting from murrayazoline as shown in fig. 12.

The structures of other members of these $\mathrm{C}-23$ alkaloids with a $\mathrm{C}_{10}$ unit forming a $\Delta^{3}$-pyran ring are shown in fig. 14.

The structure of an interesting hexacyclic base bicyclomahanimbine has been advanced [26] as (XLVIII) instead of (XLVII) on the basis of the X-ray Crystal Structure of cannabicyclol (L).

\section{Antibiotic Properties of the Alkaloids}

The antibiotics from higher plants have been subject of numerous investigations since the pioneering work by Osborn [20-22]. It is still a matter of experience that few compounds from higher plant sources have been found substantially promising as compared with the antibiotics of microbial origin. Previously, we found that some natural coumarins have antibiotic action. Since carbazole alkaloids formed a new group of plant products, we examined the antibiotic action of some of its members. The antibiotic properties of the carbazole alkaloids and some related products have been tested by the agar cup assay method using Sabourad's medium against Microsporum gypseum, Trichophyton rubrum, Epidermophyton floccusum, Candida albicans, Candida tropicalis, Staphyllococcus aureus and Escherichia coli. Glycozoline, 1-methyl-6-hydroxy carbazole, glycozolidine, 1-hydroxy carbazole, 2:6-dihydroxy-3-methyl carbazole, murraya- nine, girinimbine, mahanimbine and heptazoline were active at a concentration of $10 \mu \mathrm{g} / \mathrm{ml}$. The most significant action was observed with 6-hydroxy-3-methyl carbazole which could inhibit the growth of Trichophyton rubrum at 10 $\mu \mathrm{g} / \mathrm{ml}$. Girinimbine was active against Nocardia asteroids at a concentration of $30 \mu \mathrm{g} / \mathrm{ml}$.

A most relevant point that may be mentioned here is that mahanimbine and cannabichromene have the same monoterpene unit which undergoes similar cyclisation to yield compounds having polycyclic structure but the structural element responsible for psychomimetic drug action (THC) [17] (LI) has not so far been reported in the mahanimbine series.

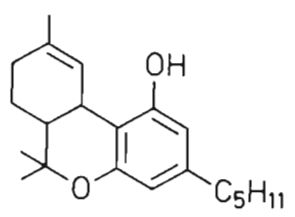

LI

\section{Biogensis of carbazole alkaloids}

The cooccurrence of furanoquinoline and acridone bases together with glycozoline and glycozolidine was conceived as circumstantial evidence in favour of the anthranilate origin of these alkaloids like many alkaloids of Rutaceae. The carbazole alkaloids have invariably a five carbon fragment. Similar five carbon fragments have been encountered in the aromatic plant constituents of the anthraquinone group. ZENK and LeIsTner [23] had shown that mevalonic acid participates in the formation of the aromatic ring 
of Rubiaceae anthraquinones. Further it is well known that in the indole alkaloids the monoterpene unit derived from the mevalonate participates in the formation of ring $C$, ring $D$ and ring $E$ of the indole alkaloids [24].

In consideration of these facts the present author suggested that the ring $\mathrm{C}$ carrying the extra methyl group may be a contribution from mevalonic acid. The mevalonate participation in building the ring $\mathrm{C}$ of the carbazole alkaloids was also conceived by ErdTMan, Popi. and Kapil as well as by NarashimHan [7].

ERDTMAN pointed out that carbazoles could originate from a 3-prenylated quinoline via 2-prenylated indole. Kurfé et al. postulated that the indole ring could arise from anthranilic acid via dimethyl allyl quinolines and subsequent ring contraction. NarashimHan however considers that tryptophan is the substrate to which the $\mathrm{C}_{5}$-unit initially attacks the 3-position of the heterocyclic system. Subsequently cyclisation and loss of serine residue in presence of pyridoxal coenzyme give a dihydrocarbazole which on dehydrogenation yields a 3-methyl carbazole.

Popli and KapIL carried out feeding experiments to provide evidence in favour of the mevalonate origin of the ring carrying the extra methyl group. Feeding of $2-{ }^{14} \mathrm{C}$ and $2-{ }^{3} \mathrm{H}$ mevalonic acid lactone tp Murraya koenigii resulted in the isolation of highly radioactive koenimbine and koenigicine (fig. 9) as well as mahanimbine (fig. 11) though the experiment establishing the location of the radioactivity is lacking.

The isolation of 3-mfthyl carbazole XIII from the genus Clausena [7] provides circumstantial evidence to this idea. The recent isolation of 3-methyl anthra- quinone from the stem bark of Clausena heptaphylla by us has a strong relevance to tie mevalonoid origin of $\mathrm{C}_{5}$-unit of 3methyl carbazole.

The oxidative functional variants of the $\mathrm{C}$-methyl group at 3-position i.e. $\mathrm{CHO}, \mathrm{COOH}, \mathrm{COOMe}$ has also been encountered in this group of alkaloids. So far the report on the occurrence of the hydroxy methyl group at 3-position was however lacking. Recently we [25] have isolated a compound having the hydroxymethyl group at 3-position. Anthraquinone derivatives have such an assembly of oxidative variants of the aromatic methyl groups in different compounds.

The occurrence of pyran ring in $C_{18}$ and $\mathrm{C}_{23}$ carbazole alkaloids could be rationalised by assuming the incorporation of a mevalonate or monoterpene unit as has been found in maoy phenolics. Heptaphylline (fig. 10), girinimbine (fig. 6), murrayacine (fig. 14) and their congeners are typical members with modified MVA unit. The co-occurrence of girinimbine and heptaphylline in Clausena heptaphylla may be considered as circumstantial evidence in favour of the origin of the pyran ring from a prenylated congener. In monoterpenoid carbazoles, the monoterpene unit gives rise to pyranoid alkaloids by cyclising to typical citran [26] and cyclol groups resulting in pentacyclic and hexacyclic bases.

It is evident that all the pyranocarbazoles have a 2-hydroxy 3-methyl carbazole skeleton. Popts et al. suggested that 2-hydroxy-3-methyl carbazole plays a prominent role in building the pyrano carbazoles. The occurrence of mukonidine (see fig. 5) in Murraya koenigii provides strong credence to this idea. Hydroxylation of the carbazole ring may result 
at the electrophilic centres at 3 or 1 positions.

It was therefore, of interest to us to look for the biomimetic [27] hydroxylation studies with 3-methyl carbazole as the substrate. Nuclear oxidation of 3methyl carbazole was carried out with FENTON's reagent as well as with the UDEN. FRIEND system (ascorbic acid, ferrous sulphate, $\mathrm{H}_{2} \mathrm{O}_{2}$, EDTA and molecular oxygen), producing (a) a colourless compound, $\mathrm{mp} 280^{\circ}, \mathrm{M}^{+} 374$, a dimeric carbazole, (b) 2-Hydroxy-3-methyl carbazole, (c) a compound, $\mathrm{mp} 185^{\circ}$ which had colour reactions characteristic for aldehydes and had the UV spectrum characteristic for 3-formyl carbazole system, and (d) 1-hydroxy-3-methyl carbazole, mp $150^{\circ}$.

The IR spectrum of the dimeric carbazole showed the absence of - NH - or hydroxyl function but the UV spectrum showed it to be a 2-oxygenated carbazole derivative. From all these data the dimeric compound could be represented by the following structure LII.<smiles>Cc1cc2c3ccccc3n3c2cc1oc1cc(C)c2cc2n3c2ccccc12</smiles>

LII

The results of this biomimetic oxidation show that hydroxylation of 3-methyl carbazole gives 2-hydroxy-3-methyl carbazole as the major hydroxylated product. It appears from the formation of an aldehydic substance that during hydroxylation the aromatic methyl group may be oxidised to formyl group. The oxidation of toluene to benzyl alcohol under modified UDENFRIEND reaction could be cited as a precendence. The lower yield $\frac{\pi}{2}$ of 1-hydroxy carbazole could probably be due to the fact that it occupies a posi- $-\frac{0}{0}$ tion meta to the methyl group.

These experiments provide a rational basis for the production of larger amount of 2-oxygenated carbazole and support the idea that 3-methyl carbazole is the progenitor of other carbazole alkaloids. Further work may reveal dimeric carbazoles in nature. The following Table. shows the occurrence of the different types of carbazole alkaloids in different genera.

\section{Table I}

Distribution of carbazole alkaloids (Fam. Rutaceae sub-fam. Aurantoidea; sub-tribe (lauseneae)

\begin{tabular}{ll}
\hline Genus & Alkaloids \\
\hline Glycosmis & $\mathrm{C}_{13}$ \\
Clausena & $\mathrm{C}_{13}$ and $\mathrm{C}_{18}$ \\
Murraya & $\mathrm{C}_{13}, \mathrm{C}_{18}$ and $\mathrm{C}_{23}$
\end{tabular}

It is evident that in closely related plants of the Fam. Rutaceae (sub fam: Aurantoidae; subtribe Clauseneae) carbazole alkaloids have been found to occur.

\section{Conclusions}

We have presented the results of some. investigations with plants of close taxonomic kinship and interesting compour.'s of sufficient biogenetic implications have been obtained. They show that a molecular taxonomic approach in 
phytochemistry is fruitful for developing biogenetic concepts and in this area substantial biosynthetic work has not yet been carried out.

\section{References}

1. Lawrence, G. H. M.: Taxonomy of Wascular Plants, p. 556 The Macmillan Company, 1958.

2. Engler, A. and L. Diels: In Syllabus der Pflanzen Familien (1936).

3. (a) Hutchison, J.: The Families of Flowering Plants, Vol 1, London, 1959, Oxford University Press.

(b) Hutchinson, J.: Evolution and Phylogeny of Flowering Plants, 1969, Acad. Press.

4. Rendle, A. B.: Classification of Flowering Plants, 2, p. 283, 1938, Cambridge.

5. Price, J. R.: Fortschritte d. Chem. Org. Naturst. 13, 302 (1955).

6. Price, J. R.: Chemical Plant Taxonomy, p. 429, 1963 (Ed T. Swain) Acad. Press.

7. Chakraborty, D. P.: Fortschritte d. Chem. Org. Naturst. 34, 299, (1977).

8. Buchi, G. and E. W. Warnhoff: J. Am. Chem. Soc. 81, 4433 (1959) and Private Communication from G. Buchi.

9. Chakraborty, D. P., J. Dutta, A. Ghosh: Science and Culture 31, 529 (1965).

10. Phillips, R. R.: Organic Reactions, 10, p. 143, N.Y. 1959 (Ed R. Adams) John Wiley \& Sons.

11. Willhalm, B., A. F. Thomas and F. Gautschi: Tetrahedron 20, 1185 (1964).

12. Narashimhan, N. S., M. V. Paradkar, P. Chittiguppi: Tetrahedron Letters 5502 (1968).

13. Joshi, B. S., V. N. Kamat and D. H. Gawad: Tetrahedron 26, 1475 (1970).
14. Kureel, S. P., R. S. Kapil and S. P. Popli: Tetrahedron Letters 3857 (1969).

15. Dutta, N. L., C. Quassim and M. S. Wadia: Indian J. Chem. 7, 307 (1969).

16. Bordner, J., D. P. Chakraborty, B. K. Choudhury, S. N. Ganguli, K.C. Das and B. Weinstein: Experientia 28, 1406 (1972).

17. Mechoulam, R. and Y. Gaoni: Fortschr. d. Chem. Organ. Naturstoffe 25, 175 (1967).

18. Mechoulam, R., Neil. K. Mccallum, S. Burstein: Chem. Rev. 76, 75 (1976).

19. Crombie, L., D. A. Whiting, D. G. Clarke and M. G. Begley: Chem. Comm. 1547 (1970).

20. Skinner, E. A.: In modern Methods of Plant Analysis, Vol 3, p. 626, 1955 (Ed by Peach and Tracey), Springer Verlag.

21. Nickell, L. G.: Econ. Bot. 13, 281 (1959).

22. (a) Chakraborty, D. P., A. Dasgupta and P. K. Bose: Ann. Bio-Chem. exp. Med. 17, 59 )1957).

(b) Chakraborty, D. P., M. Sen and P. K. Bose: Trans. Bose. Inst. 24, 31 (1961).

23. Leistner, E. and M. H. Zenk: Tetrahedron Letters 1395 (1968).

24. Battersby, A. R., R. T. Brown, R. S. Kapil, A. O. Plumkelt, J. B. Taylor: Chem. Comm. 46 (1966).

25. Roy, S., L. Bhattacharyya and D. P. Chakraborty - unpublished data.

26. Begley, M. J., L. Crombie, R. W. King, D. A. Slack and D. A. Whiting: J. Chem. Soc. Penkin I 2393 (1977).

27. Marsuna, T.: Tetrahedron, 33, 2869 (1977). 